\title{
ACUTE SUICIDAL POISONING BY ALUMINUM PHOSPHIDE: RARE CASE REPORT FROM NORTHERN RURAL INDIA
}

\author{
KANIKA KOHLI ${ }^{1}$, RANJODH JEET SINGH ${ }^{2 *}$, SONIA KOCHHAR ${ }^{3}$
}

${ }^{1}$ Department of Forensic Medicine, Maharishi Markandeshwar Institute of Medical Sciences and Research, Maharishi Markandeshwar Deemed to be University, Mullana, Haryana, India. ${ }^{2}$ Department of Pharmacology, Maharishi Markandeshwar Institute of Medical Sciences and Research, Maharishi Markandeshwar Deemed to be University, Mullana, Haryana, India. ${ }^{3}$ Department of Physiology, All India Institute of Medical Sciences, Bathinda, Punjab, India. Email: ranjotsmith1986@gmail.com

Received: 26 May 2021, Revised and Accepted: 30 June 2021

\section{ABSTRACT}

Aluminum phosphide (ALP) is a highly toxic pesticide and is lethal if abused as a suicidal agent invariably. The ALP or a celphos powder is a major contributor to mortality, as such celphos poisoning lacks a specific antidote. The management of the patients includes fast decontamination and all international protocol supportive measures. The ALP poisoning has gained enormous interest with the spike in the number of cases due to its increased use for non-agricultural purposes as well. The easy ease of availability and laxity in the implementation of the sale of pesticides has eventually led to misuse, rather an abuse for the commitment of suicide. Celphos powder is commonly available in the form of tablets. This is a case of suicidal consumption of ALP by 54 years old male, a farmer by occupation. According to our interpretation, we believe that strict implementation of pesticide laws must be enforced and suicide help awareness programs under the banner of government and non-government organizations must come in the front line up.

Keywords: Aluminum phosphide, Phosphine, Celphos powder, Poisoning, Suicide, Magnesium sulfate, Potassium permanganate, Agricultural farmers, Decontamination.

(C) 2021 The Authors. Published by Innovare Academic Sciences Pvt Ltd. This is an open access article under the CC BY license (http://creativecommons.org/ licenses/by/4.0/) DOI: http://dx.doi.org/10.22159/ajpcr.2021v14i8.42193. Journal homepage: https://innovareacademics.in/journals/index.php/ajpcr

\section{INTRODUCTION}

Pesticide poisoning is a major public health issue in the rural parts of the Asian population, in whom morbidity and mortality are extremely high as compared to the developed world. The availability of aluminum phosphide (ALP) in agricultural setup and that too at very nominal cheap price poses a more threat. The ALP poisoning is generally suicidal, most likely accidental, and homicidal [1]. The active form of ALP is phosphine trihydride and hydrogen phosphide which is released when phosphide grains mix with the moisture. The combination of phosphide with acid is extremely dangerous as it releases more phosphine. The formulations are available in form of tablets, compressed discs containing phosphide, pellets. The acute poisoning of ALP poisoning could be directly due to ingestion, consumption of phosphides, or inhalation of phosphine, which is released during its use in the agricultural sector [2,3]. The clinical symptomatology of ALP poisoning generally includes refractory hypotension, progressive metabolic acidosis, dysrhythmia, gastrointestinal disturbances [4]. The first case of ALP poisoning was reported in the year 1981 in India, and then ALP count is on an exponential rise, particularly in rural parts of central India and Northwest India, due to poor regulatory measures and lack of awareness in context with toxic compound [5]. The lethal dose of ALP is $10 \mathrm{mg} / \mathrm{kg}$. In a developing country such as India, most of the patients succumb due to the toxicity of ALP. The institutional ethics committee approval was taken before the commencement of the case study. This case report we aimed at reporting keeping in view public health as ALP poisoning may reoccur although it is rare and uncommon.

\section{CASE REPORT}

A 54-year-old male farmer was admitted to the emergency department with the chief complaints of colicky pain in the epigastric region, shortness of breath, dizziness, weakness, sweating. On examination of the patient, the vital signs recorded were blood pressure - 102/68 mmHg, Respiratory rate $-22 /$ min, Oxygen saturation - $93 \%$, and pulse rate $-88 / \mathrm{min}$. The patient was peripherally cyanosed and cold clammy skin. On proper history taking the patient was having a history of hypertension and diabetes mellitus. The abdomen examination demonstrated colonic tenderness, rigidity, and hepatomegaly. Cardiovascular examination revealed tachycardia and prolongation of QTC interval was an important finding of his electrocardiogram. The laboratory investigations concluded normal renal function tests with normal serum levels of calcium, magnesium, potassium, and sodium. On the contrary liver function tests were deranged. Serum glutamic oxaloacetic transaminase was $74.4 \mathrm{IU} / \mathrm{L}$ and serum glutamic pyruvic transaminase was 73 IU/L. A complete hemogram, as well as urine examination, was performed which was found to be normal. The patient was managed with enough hydration with I.V. fluids, oxygen therapy with resuscitation measures blended with positive pressure ventilation. Injection magnesium sulfate, injection hydrocortisone, and other supportive measures were performed. Subcutaneous insulin was given for the management of high blood sugar levels.

While the emergency staff and doctors kept at the conversation with the patient and relatives/attendants this poisoning was found to be suicidal. The opinion was concluded with the proper history given by the patient and his relatives, and also by relevant medical examination, laboratory examination/investigations performed post-arrival of the patient. Furthermore, the empty sachet of ALP was brought by the patient relatives. The patient was also called for a psychiatric examination which showed depressive mood, irritability, thought derangements, not properly oriented to time, place, and person, suicidal tendency. Later after 2 weeks, the patient showed significant improvement and laboratory investigations were approaching back to normal.

\section{DISCUSSION}

Acute ALP poisoning is a worldwide public health concern. The knowledge in context with its mechanism of action/toxicity and clinical symptomatology has improved in recent times. However, still, there is an unavailability of an antidote for ALP poisoning. The ALP is a solid pesticide that has been used in India for decades for agricultural purposes. The ease of availability and that too at cheaper rates with brand names 
celphos, phosphotex, and alphos. Exposure to ALP leads to the release of phosphine gas which is extremely toxic and may prove fatal. In Asia, approximately 25 million agricultural farmers report poisoning every year [6]. 188 poisoning cases of ALP were reported in Germany between 1986 and 2003, out of these $28 \%$ were intentional whereas $65 \%$ cases were accidental as exposure by inhalation [7]. The non-availability of antidote and severe poisoning may cause death in approximately $3 \mathrm{~h}$. The clinical symptomatology depends on the mode of exposure to poison and the duration of exposure to ALP. The rapid systemic toxicity is with phosphine gas as it is very fastly absorbed. The mechanism of action of ALP is still not known properly. In certain animal studies, it is demonstrated that phosphine binds to cytochrome oxides and alters the haem component of hemoglobin [8]. The induction of oxidative stress results in protein denaturation of the cell membrane $[9,10]$. The systemic complications of phosphide poisoning, methemoglobinemia, and hemolysis which is evidence of the involvement of erythrocytes in the biotransformation of phosphine in humans [11]. The phosphine gas is excreted as hypophosphite in urine and exhaled in unchanged form [12]. The toxicity ranges from mild to severe forms. The early clinical features include epigastric pain, vomiting, and nausea. The early manifestations of severe fatal toxicity are a circulatory failure and shock [13]. The gastrointestinal symptoms of ALP poisoning include vomiting, epigastric pain, and haematemesis. Dysphagia could also be presented as a late complication of ALP poisoning [14-18]. The metabolic and electrolyte disturbances are presented as metabolic acidosis, hypokalemia, and respiratory alkalosis, or even as renal failure [11]. These electrolyte and metabolic abnormalities cause an extremely high mortality rate [19]. The other peculiar signs and effects of ALP poisoning include hepatitis, pancreatitis, disseminated intravascular coagulation, acute tubular necrosis [11]. The shock may cause cerebral anorexia that usually presents as delirium, drowsiness, and coma [20,21]. In the 1990s ALP was considered as one of the leading causes of suicidal death in northern parts of India. The ALP has no proper antidote pharmacotherapy, thus early intervention with proper resuscitative and supportive features is important for better outcomes and a good prognosis for sequelae of ALP poisoning the patients.

\section{CONCLUSION}

The treatment module of ALP poisoning must be aggressive/fast pharmacotherapy with gastric lavage. Before initiation of treatment medical staff must be wearing the full face mask and surgical gloves and must protect themselves from any exposure to phosphine gas. The contaminated clothes must be removed throughout and decontamination of skin and other natural orifices must be done with irrigation and copious amounts of saline. Gastric lavage with potassium permanganate activated charcoal and sorbitol solution. The administration of intravenous fluids for hemodynamic support and maintenance of physiological systems must be equipped. The appropriate measure must be taken by government regulatory authorities for the sales and distribution of ALP. The awareness camps amongst the agricultural farmers must be conducted for pesticide use and safe disposal. To improve the patient's outcome, the patient's attendants and the families must bring poison/poison packets/sachets along with them to the hospital. The ALP poisoning could be prevented by proper follow-up and rehabilitation/counseling of the patients to prevent suicidal tendencies.

Declaration of the patient consent: The authors certify that they have obtained all appropriate the patient consent forms. In the consent form, the patient's clinical information to be reported and published in this journal. The patient understands that their names and initials will not be published and due efforts will be made to conceal their identity, but anonymity cannot be guaranteed.

\section{ACKNOWLEDGMENT}

The author wants to acknowledge and express their appreciation with a special note of thanks to Dr. Sonia Kochhar, Associate professor, and head of department, AIIMS, Bathinda, Punjab as an author's contribution throughout supervision and preparation of the manuscript.

\section{AUTHORS CONTRIBUTIONS}

All authors have contributed to the preparation of the manuscript. All authors discussed the casework throughout conductance of work, monitoring, and interpretation of work. All authors discussed the case report, revised and commented in the manuscript. All authors approved the final version of the manuscript.

\section{CONFLICTS OF INTEREST}

The authors declare no conflicts of interest.

\section{AUTHORS FUNDING}

Nil.

\section{REFERENCES}

1. Kumar A, Pathak A, Verma A, Kumar S. Accidental inhalational poisoning by multiple pesticides of the organophosphorus group in an ages person: An uncommon occurrence. J Forensic Med Toxicol 2012;29:78-83.

2. Mehrpour O, Amouzeshi A, Dadpour B, Oghabian Z, Zamani N, Amini S, et al. Successful treatment of cardiogenic shock with an intraaortic balloon pump following aluminum phosphide poisoning. Arch Ind Hyg Toxicol 2014;65:121-7.

3. Soltaninejad K, Nelson LS, Bahreini SA, Shadnia S. Fatal aluminum phosphide poisoning in Tehran-Iran from 2007 to 2010. Indian J Med Sci 2012;66:66-70.

4. Bogle RG, Theron P, Brooks P, Dargan PI, Redhead J. Aluminium phosphide poisoning. Emerg Med J 2006;23:e03.

5. Meena HS, Murthy OP, Bose S, Bhatia S, Dogra TD. Aluminum phosphide poisoning. J Forensic Med Toxicol 1989;11:19-30.

6. Jeyaratnam J. Acute pesticide poisoning: A major global health problem. World Health Stat Q 1990;43:139-44.

7. Lauterbach M, Solak E, Kaes J, Wiechelt J, Von Mach MA, Weilemann LS. Epidemiology of hydrogen phosphide exposures in humans reported to the poison center in Mainz, Germany, 1983-2003. Clin Toxicol (Philia) 2005;43:575-81

8. Price NR, Moles KA, Humphires OA. Phosphine toxicity and catalase activity in susceptible and resistant strains of lesser grain borer (Rhyzopertha dominica). Comp Biochem Physiol 1982;73:411-5.

9. Chugh SN, Arora V, Sharma A, Chugh K. Free radical scavengers and lipid peroxidation in acute aluminum phosphide poisoning. Indian $\mathrm{J}$ Med Res 1996;104:190-3.

10. Dua R, Gill KD. Aluminum phosphide exposure: Implications on rat brain lipid peroxidation and antioxidant defense system. Pharmacol Toxicol 2001;89:315-9.

11. Proudfoot AT. Aluminum and zinc phosphide poisoning. Clin Toxicol (Philia) 2009;47:89-100.

12. Gurjar M, Baronia AK, Azim A, Sharma K. Managing aluminum phosphide poisonings. J Emerg Trauma Shock 2011;4:378-84.

13. Singh RB, Singh RG, Singh U. Hypermagnesemia following aluminum phosphide poisoning. Int J Clin Pharmacol Ther Toxicol 1991;29:82-5.

14. Chugh SN, Dushyant, Ram S, Arora B, Malhotra KC. Incidence and outcome of aluminum phosphide poisoning in a hospital study. Indian J Med Res 1991;94:232-5.

15. Chhina RS, Thukral R, Chawla LS. Aluminum phosphide-induced gastroduodenitis. Gastrointest Endosc 1992;38:635-6.

16. Nijhawan S, Rastogi M, Tandon M, Mathur A, Rai RR. Aluminum phosphide induced esophageal stricture: an unusual complication. Endoscopy 2006;38 Suppl 2:E23

17. Talukdar R, Singal DK, Tandon RK. Aluminum phosphide induced esophageal stricture. Indian J Gastroenterol 2006;25:98-9.

18. Madan K, Chalamalasetty SB, Sharma M, Makharia G. Corrosive-like strictures caused by ingestion of aluminum phosphide. Natl Med J India 2006;19:313-4.

19. Mehrpour O, Shadnia S, Soltannejad K, Yaghmaei A. Evaluation of electrolytes and blood glucose level in aluminum phosphide poisoning. Sci J Forensic Med 2009; 15:49-53.

20. Shadnia S, Soltaninejad K, Hassanian-Moghadam H, Sadeghi A, Rahimzadeh $\mathrm{H}$, Zamani N, et al. Methemoglobinemia in aluminum phosphide poisoning. Hum Exp Toxicol 2011;30:250-3.

21. Mostafazadeh B, Pajoumand A, Farzaneh E, Aghabiklooei A, Rasouli MR. Blood levels of methemoglobin in patients with aluminum phosphide poisoning and its correlation with patient's outcome. J Med Toxicol 2011;7:40-3 